\title{
The effect of temperature and water on secondary organic aerosol formation from ozonolysis of limonene, $\Delta^{3}$-carene and $\alpha$-pinene
}

\author{
Å. M. Jonsson, M. Hallquist, and E. Ljungström \\ Department of Chemistry, Atmospheric Science, University of Gothenburg, 41296 Gothenburg, Sweden
}

Received: 17 March 2008 - Published in Atmos. Chem. Phys. Discuss.: 23 May 2008

Revised: 5 September 2008 - Accepted: 19 September 2008 - Published: 14 November 2008

\begin{abstract}
The effect of reaction temperature and how water vapour influences the formation of secondary organic aerosol (SOA) in ozonolysis of limonene, $\Delta^{3}$-carene and $\alpha$-pinene, both regarding number and mass of particles, has been investigated by using a laminar flow reactor (G-FROST). Experiments with cyclohexane and 2-butanol as $\mathrm{OH}$ scavengers were compared to experiments without any scavenger. The reactions were conducted in the temperature range between 298 and $243 \mathrm{~K}$, and at relative humidities between $<10$ and $80 \%$. Results showed that there is still a scavenger effect on number and mass concentrations at low temperatures between experiments with and without an addition of an $\mathrm{OH}$ scavenger. This shows that the $\mathrm{OH}$ chemistry is influencing the SOA formation also at these temperatures. The overall temperature dependence on SOA formation is not as strong as expected from partitioning theory. In some cases there is even a positive temperature dependence that must be related to changes in the chemical mechanism and/or reduced rates of secondary chemistry at low temperatures. The precursor's $\alpha$-pinene and $\Delta^{3}$-carene exhibit a similar temperature dependence regarding both number and mass of particles formed, whereas limonene shows a different dependence. The water effect at low temperature could be explained by physical uptake and cluster stabilisation. At higher temperatures, only a physical explanation is not sufficient and the observations are in line with water changing the chemical mechanism or reaction rates. The data presented adds to the understanding of SOA contribution to new particle formation and atmospheric degradation mechanisms.
\end{abstract}

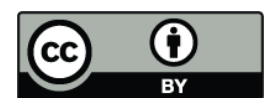

Correspondence to: M. Hallquist (hallq@chem.gu.se)

\section{Introduction}

Vegetation emits a vast number of biogenic volatile organic compounds (BVOC), where isoprene and the monoterpenes are the non methane BVOC that dominate on the global scale (Guenther, 2002). In the atmosphere they undergo oxidation, forming compounds with low volatility that can end up in the condensed phase by gas-to-particle conversion (Griffin et al., 1999; Yokouchi and Ambe, 1985). It has long been known that oxidation of biogenic organic compounds can form aerosol particles (Went, 1960). However, the actual formation mechanism behind these compounds of low volatility, their identity and their properties are still unresolved issues (Goldstein and Galbally, 2007). Even more so, the secondary organic aerosol (SOA) formation from BVOC at temperatures below room temperatures is not well documented (Jang and Kamens, 1999; Pathak et al., 2007b; Saathoff et al., 2008). This includes how temperature affects gas-to-particle partitioning, the oxidation mechanism and the influence of water and $\mathrm{NO}_{\mathrm{x}}$. Indeed, further investigations of the temperature dependence of SOA formation from BVOC oxidation are important, especially in order to provide a proper description of SOA in climate models (Kanakidou et al., 2005; Tsigaridis and Kanakidou, 2003). An important oxidation route for unsaturated BVOC, such as the monoterpenes $\left(\mathrm{C}_{10} \mathrm{H}_{16}\right)$, is by reaction with ozone, i.e. ozonolysis. The other major routes are reaction with $\mathrm{OH}$ and $\mathrm{NO}_{3}$ radicals. The ozone initiated degradation has received considerable attention in numerous studies, as summarised by e.g. Calvert et al., 2000; Atkinson and Arey, 2003. A complication in the ozone degradation mechanism is the production of $\mathrm{OH}$ radicals. This implies the need to either consider both oxidants $\left(\mathrm{O}_{3}\right.$ and $\left.\mathrm{OH}\right)$ or suppress the $\mathrm{OH}$ chemistry by using a so called $\mathrm{OH}$ scavenger in laboratory experiments. However, it has been shown that the use of $\mathrm{OH}$ scavengers and which scavengers used can influence the SOA formation (Jonsson et al., 2008; Keywood et al.,

Published by Copernicus Publications on behalf of the European Geosciences Union. 
2004). The detailed temperature dependence of SOA formation from ozonolysis of terpenes and its properties has been investigated in relatively few, recent studies (Burkholder et al., 2007; Jang and Kamens, 1999; Jenkin, 2004; Jonsson et al., 2007; Pathak et al., 2007b). These investigations were based on smog chamber experiments and modelling. There are different approaches when studying SOA formation and its temperature dependence. One is to keep the reaction system at the temperature of interest followed by monitoring the aerosol production with instrumentation at room temperature (Saathoff et al., 2008). Another is to maintain the analytical instrumentation at the same temperature as the reaction system (Jonsson et al., 2006; Takekawa et al., 2003). A third method is to specifically investigate the gas-to-particle partitioning by making a rapid change in temperature after producing the SOA at an initial temperature (Pathak et al., 2007b). These different ways of conducting smog chamber studies give valuable information e.g. on the relationship between partitioning effects and changes in chemical kinetics and mechanisms due to temperature. A specific evaluation method has evolved for smog chamber partitioning data, where the SOA yield, expressed as mass of SOA per amount reacted organics, is related to the mass of organic material allocated for gas-to-particle partitioning (Odum et al., 1996; Pankow, 1994). This approach is based on the assumption that each compound is partitioning according to Raoult's law, and an organic material partitioning coefficient, $K_{o m, i}$, can be derived for each compound (i) according to Eq. (1).

$K_{\text {om }, i}=\frac{R T f_{\mathrm{om}}}{M W_{\mathrm{om}} \zeta_{i} p_{i}^{o}}$

Here $f_{\text {om }}$ is the fraction of the total suspended particulate concentration being organic material (om). $M W_{\mathrm{om}}$ is the average molecular mass of the condensed organic matter, $T$ is temperature, $R$ is the common gas constant, $\zeta_{i}$ is the activity coefficient and $p_{i}^{o}$ the vapour pressure of the pure compound $i$. The SOA formation in an experiment can then be parameterised using the assumption of two or more hypothetical products contributing to the produced aerosol (Odum et al., 1996). Although, for smog chamber results one semivolatile and one low volatility product are often enough. Each compound is represented by a stoichiometric coefficient, $\alpha_{i}$, and a partitioning coefficient, $K_{\mathrm{om}, \mathrm{i}}$. The resulting yield, Y, can be parameterised by using Eq. (2):

$Y=M_{0}\left(\frac{\alpha_{1} K_{\mathrm{om}, 1}}{1+K_{\mathrm{om}, 1} M_{0}}+\frac{\alpha_{2} K_{\mathrm{om}, 2}}{1+K_{\mathrm{om}, 2} M_{0}}\right)$

However, it has proven to be a delicate matter to compare the parameterisation between different studies (Pathak et al., 2007a). As an alternative, Donahue et al. (Donahue et al., 2006) recently presented a multi product basis set approach, which was applied e.g. by Pathak et al. (2007a) to parameterise $\alpha$-pinene ozonolysis using smog chamber data from selected studies. These achievements are promising in describing SOA mass formation from ozonolysis of $\alpha$-pinene for specific conditions.

Several studies have focused on developing a mechanistic understanding of ozonolysis of terpenes by using rather complex chemical models (Camredon et al., 2007; Jenkin, 2004). However there is still a need for validation by using results from smog chamber experiments and/or additional approaches e.g. flow reactor studies. While data from such experiments will be useful for chemical mechanism development, they will also provide input for development of proper model descriptions of aerosol mass and new particle formation (Burkholder et al., 2007). New particle formation is dependent on several aspects where the rate of production of low volatility material and degree of supersaturation reached are central (Anttila et al., 2004).

In the present study, data are presented that can be used in all three approaches described above, i.e. SOA mass formation, evaluation of chemical mechanisms and for comparison of nucleation efficiency. The laminar flow reactor method used here is a complement to smog chamber experiments with uniqueness in several aspects e.g. stability in concentrations, temperature and humidity as well as the fact that the aerosol formation is "frozen in time" and the possibility to investigate SOA at high relative humidity (RH) (Jonsson et al., 2006; Jonsson et al., 2008). In addition to investigation of $\alpha$-pinene also limonene and $\Delta^{3}$-carene were studied, all of which are important BVOC compounds in the atmosphere (Guenther et al., 1995). The present work covers an extensive temperature (243-298 K) and relative humidity range (10$80 \%$ ) as well as the use of $\mathrm{OH}$ scavengers. Both new particle formation and SOA mass production were evaluated with respect to the chemical degradation mechanism.

\section{Experimental}

\subsection{The experimental setup}

These experiments were conducted by using the G-FROST set-up (Göteborg-Flow Reactor for Oxidation Studies at low Temperatures), which is a combination of a laminar flow reactor and a Scanning Mobility Particle Sizer (SMPS, TSI Model 3936) system. The setup, procedure and analysis have been described in detail elsewhere (Jonsson et al., 2006), and is only briefly presented here. The reactor is a vertically positioned glass cylinder of $1.91 \mathrm{~m}$ length and $10 \mathrm{~cm}$ diameter, housed in a temperature controlled chamber with an available working temperature range between 243 and $323 \mathrm{~K}$. Ozone is added to the reactor separated from the flow containing the organic precursors through a movable injector. The addition of the terpenes and the $\mathrm{OH}$ scavenger is performed by flowing $\mathrm{N}_{2}$ through gas-wash bottles containing the substances and the concentration is controlled by varying the temperature of the bottles. In order to enable low concentrations of 
Table 1. Experimental Conditions. [Terpene $]_{0}$ and $\left[\mathrm{O}_{3}\right]_{0}$ are initial concentrations. The $\mathrm{RH}$ was varied between the given limits in up to four steps. Stated errors are at the statistical $95 \%$ confidence level. A possible systematic error for $[\text { Terpene }]_{0}$, and $\left[\mathrm{O}_{3}\right]_{0}$ is about $20 \%$.

\begin{tabular}{|c|c|c|c|c|c|c|}
\hline Exp & Organic Precursor & OH Scavenger & Temperature (K) & {$[\text { Terpene }]_{0} 10^{11}$ molecules $\mathrm{cm}^{-3}$} & {$\left[\mathrm{O}_{3}\right]_{0} 10^{13}$ molecules $\mathrm{cm}^{-3}$} & $\mathrm{RH}(\%)$ \\
\hline 1 & Limonene & 2-butanol & $298.3 \pm 0.1$ & $6.56 \pm 0.23$ & $1.27 \pm 0.01$ & $12.1-75.9$ \\
\hline 2 & Limonene & cyclohexane & $298.3 \pm 0.1$ & $6.56 \pm 0.23$ & $1.27 \pm 0.01$ & $11.8-75.6$ \\
\hline 3 & Limonene & None & $298.2 \pm 0.1$ & $6.56 \pm 0.23$ & $1.27 \pm 0.01$ & $9.5-69.3$ \\
\hline 4 & Limonene & 2-butanol & $272.3 \pm 0.1$ & $6.22 \pm 0.22$ & $1.48 \pm 0.01$ & $20.9-79.6$ \\
\hline 5 & Limonene & cyclohexane & $272.3 \pm 0.1$ & $6.22 \pm 0.22$ & $1.48 \pm 0.01$ & $20.2-86.5$ \\
\hline 6 & Limonene & None & $272.3 \pm 0.1$ & $6.22 \pm 0.22$ & $1.48 \pm 0.01$ & $21.4-83.6$ \\
\hline 7 & Limonene & 2-butanol & $243.6 \pm 0.3$ & $5.91 \pm 0.21$ & $1.74 \pm 0.01$ & $49.3-67.4$ \\
\hline 8 & Limonene & cyclohexane & $244.2 \pm 0.3$ & $5.91 \pm 0.21$ & $1.74 \pm 0.01$ & $47.5-\sim 70$ \\
\hline 9 & Limonene & None & $243.0 \pm 0.4$ & $5.91 \pm 0.21$ & $1.74 \pm 0.01$ & $42.4-72.3$ \\
\hline 10 & $\Delta^{3}$-Carene & 2-butanol & $298.0 \pm 0.1$ & $6.10 \pm 0.28$ & $6.81 \pm 0.01$ & $9.5-74.2$ \\
\hline 11 & $\Delta^{3}$-Carene & cyclohexane & $298.0 \pm 0.1$ & $6.10 \pm 0.28$ & $6.81 \pm 0.01$ & $10.5-75.8$ \\
\hline 12 & $\Delta^{3}$-Carene & None & $298.0 \pm 0.1$ & $6.10 \pm 0.28$ & $6.81 \pm 0.01$ & $10.3-76.2$ \\
\hline 13 & $\Delta^{3}$-Carene & 2-butanol & $272.3 \pm 0.1$ & $5.94 \pm 0.28$ & $7.21 \pm 0.01$ & $23.8-94.7$ \\
\hline 14 & $\Delta^{3}$-Carene & cyclohexane & $272.3 \pm 0.1$ & $5.94 \pm 0.28$ & $7.21 \pm 0.01$ & $21.0-87.8$ \\
\hline 15 & $\Delta^{3}$-Carene & None & $272.3 \pm 0.1$ & $5.94 \pm 0.28$ & $7.21 \pm 0.01$ & $22.3-88.6$ \\
\hline 16 & $\Delta^{3}$-Carene & 2-butanol & $243.5 \pm 0.1$ & $5.82 \pm 0.27$ & $7.37 \pm 0.01$ & $\sim 43-\sim 79$ \\
\hline 17 & $\Delta^{3}$-Carene & cyclohexane & $243.7 \pm 0.3$ & $5.82 \pm 0.27$ & $7.37 \pm 0.01$ & $42.9-78.8$ \\
\hline 18 & $\Delta^{3}$-Carene & None & $243.5 \pm 0.1$ & $5.82 \pm 0.27$ & $7.37 \pm 0.01$ & $42.9-78.4$ \\
\hline 19 & $\alpha$-Pinene & 2-butanol & $298.0 \pm 0.1$ & $5.74 \pm 0.25$ & $2.91 \pm 0.01$ & $10.0-73.6$ \\
\hline 20 & $\alpha$-Pinene & cyclohexane & $298.0 \pm 0.1$ & $5.74 \pm 0.25$ & $2.91 \pm 0.01$ & $12.4-79.3$ \\
\hline 21 & $\alpha$-Pinene & None & $298.0 \pm 0.1$ & $5.74 \pm 0.25$ & $2.91 \pm 0.01$ & $19.6-73.7$ \\
\hline 22 & $\alpha$-Pinene & 2-butanol & $272.5 \pm 0.1$ & $6.58 \pm 0.29$ & $3.01 \pm 0.01$ & $19.1-84.6$ \\
\hline 23 & $\alpha$-Pinene & cyclohexane & $272.5 \pm 0.1$ & $6.58 \pm 0.29$ & $3.01 \pm 0.01$ & $18.4-85.9$ \\
\hline 24 & $\alpha$-Pinene & None & $272.6 \pm 0.1$ & $6.58 \pm 0.29$ & $3.01 \pm 0.01$ & $10.4-76.6$ \\
\hline 25 & $\alpha$-Pinene & 2-butanol & $245.0 \pm 0.1$ & $5.69 \pm 0.25$ & $3.57 \pm 0.01$ & $37.4-85.7$ \\
\hline 26 & $\alpha$-Pinene & cyclohexane & $245.3 \pm 0.1$ & $5.69 \pm 0.25$ & $3.57 \pm 0.01$ & $39.3-85.9$ \\
\hline 27 & $\alpha$-Pinene & None & $244.9 \pm 0.2$ & $5.69 \pm 0.25$ & $3.57 \pm 0.01$ & $38.6-82.9$ \\
\hline
\end{tabular}

the terpenes, they are kept in diffusion limited containers in the wash-bottles. The bulk flow is humidified by passing it trough a Gore-Tex tube submerged in de-ionised water and the humidity is set by the water temperature. To prevent influence of the flow closest to the reactor wall, only the centre part of the flow is sampled and conveyed via a sampling funnel positioned at the end of the flow reactor. The terpene concentration was measured before and after an experiment by sampling onto adsorbent tubes and subsequent two-step thermal desorption/GC analysis. The ozone concentration was measured by using an UV absorption analyser (Thermo Environmental Instruments Inc, model 49C).

\subsection{Experimental procedure}

The experimental conditions are summarised in Table 1 . In the experiments $2.6 \pm 0.2 \times 10^{11}$ molecules $\mathrm{cm}^{-3}$ of the terpene (limonene, $\Delta^{3}$-carene or $\alpha$-pinene) had reacted and the initial rate of reaction was $1.4 \pm 0.1 \times 10^{9}$ molecules $\mathrm{cm}^{-3} \mathrm{~s}^{-1}$. To achieve this rate of reaction, and corresponding consumption, for all the terpenes the ozone concentration was set in relation to the rate coefficient for each system. The rate coefficients used for calculating the consumption of the terpenes at $298 \mathrm{~K}$, were $200 \times 10^{-18}, 37 \times 10^{-18}, 86.6 \times 10^{-18} \mathrm{~cm}^{3}$ molecule ${ }^{-1} \mathrm{~s}^{-1}$ for limonene, $\Delta^{3}$-carene and $\alpha$-pinene respectively (Atkinson, 1994). The temperature dependence of the rate coefficients were taken from (Atkinson et al., 2006; Khamaganov and Hites, 2001). No temperature dependence of the rate coefficient for $\Delta^{3}$-carene is available in the literature. Motivated by the similarity in structure between $\alpha$-pinene and $\Delta^{3}$-carene, the temperature dependence of the rate coefficient for $\alpha$-pinene was applied to extrapolate the value at $298 \mathrm{~K}$ to the low temperatures. The average reaction time was kept identical $(242 \pm 2 \mathrm{~s})$ in all experiments, by changing the total mass flow, i.e. the volume flow in the reactor was at all times $1.64 \pm 0.01 \mathrm{LPM}$ regardless of temperature. The flow conveyed via the sampling funnel $(1.08 \pm 0.04 \mathrm{LPM})$ was also adjusted in order to keep the ratio between this flow and the total volume flow through the reactor constant in all experiments. Total particle number, $\mathrm{N}$, and total particle mass, $\mathrm{M}$, were calculated by averaging five consecutive distributions $10-300 \mathrm{~nm}$ and assuming unit density. The scan time used was 300 s (i.e. an up-scanning time of $240 \mathrm{~s}$, a down-scanning time of $45 \mathrm{~s}$ and a delay time of $15 \mathrm{~s}$ ). 
Table 2. Number (N) and mass (M) fractions of using 2-butanol and cyclohexane compared to no use of $\mathrm{OH}$ scavenger at the reaction temperatures 298,273 and $243 \mathrm{~K}$ and at a RH range of $10-80 \%$.

\begin{tabular}{|c|c|c|c|c|c|}
\hline \multirow[t]{2}{*}{ Limonene } & \multirow[t]{2}{*}{ Temp (K) } & \multicolumn{4}{|c|}{$\mathrm{N}(\mathrm{OH}-\mathrm{s}) / \mathrm{N}(\mathrm{No} \mathrm{OH}-\mathrm{s}) ; \mathrm{M}(\mathrm{OH}-\mathrm{s}) / \mathrm{M}(\mathrm{No} \mathrm{OH}-\mathrm{s})$} \\
\hline & & dry & $40 \%$ & $60 \%$ & $80 \%$ \\
\hline \multirow{3}{*}{ 2-butanol } & 298 & $0.13 ; 0.78$ & $0.14 ; 0.72$ & $0.14 ; 0.66$ & $0.15 ; 0.65$ \\
\hline & 273 & $0.61 ; 0.87$ & $0.60 ; 0.84$ & $0.58 ; 0.77$ & $0.58 ; 0.78$ \\
\hline & 243 & $0.71 ; 0.73$ & & & $0.74 ; 0.75$ \\
\hline \multirow{3}{*}{ cyclohexane } & 298 & $0.06 ; 0.40$ & $0.05 ; 0.33$ & $0.05 ; 0.32$ & $0.06 ; 0.36$ \\
\hline & 273 & $0.34 ; 0.58$ & $0.33 ; 0.59$ & $0.27 ; 0.55$ & $0.25 ; 0.58$ \\
\hline & 243 & $0.62 ; 0.59$ & & & $0.56 ; 0.59$ \\
\hline \multirow[t]{2}{*}{$\Delta^{3}$-Carene } & & dry & $40 \%$ & $60 \%$ & $80 \%$ \\
\hline & 298 & $0.16 ; 0.63$ & $0.19 ; 0.68$ & $0.21 ; 0.74$ & $0.24 ; 0.77$ \\
\hline \multirow[t]{3}{*}{ 2-butanol } & 273 & $0.32 ; 0.88$ & $0.33 ; 0.92$ & $0.31 ; 0.89$ & $0.27 ; 0.89$ \\
\hline & 243 & $0.37 ; 0.69$ & & & $0.40 ; 0.66$ \\
\hline & 298 & $0.07 ; 0.20$ & $0.06 ; 0.18$ & $0.06 ; 0.19$ & $0.07 ; 0.21$ \\
\hline \multirow[t]{2}{*}{ cyclohexane } & 273 & $0.19 ; 0.77$ & $0.18 ; 0.80$ & $0.10 ; 0.72$ & $0.13 ; 0.65$ \\
\hline & 243 & $0.36 ; 0.56$ & & & $0.38 ; 0.56$ \\
\hline \multirow[t]{2}{*}{$\alpha$-Pinene } & & dry & $40 \%$ & $60 \%$ & $80 \%$ \\
\hline & 298 & $0.07 ; 0.07$ & $0.11 ; 0.11$ & $0.15 ; 0.16$ & $0.15 ; 0.16$ \\
\hline \multirow[t]{3}{*}{ 2-butanol } & 273 & $0.11 ; 0.35$ & $0.14,0.38$ & $0.15 ; 0.38$ & $0.14 ; 0.40$ \\
\hline & 243 & $0.39 ; 0.73$ & & & $0.36 ; 0.68$ \\
\hline & 298 & $0.04 ; 0.04$ & $0.04 ; 0.05$ & $0.05 ; 0.06$ & $0.05 ; 0.06$ \\
\hline \multirow[t]{2}{*}{ cyclohexane } & 273 & $0.25 ; 0.46$ & $0.18 ; 0.44$ & $0.17 ; 0.40$ & $0.12 ; 0.37$ \\
\hline & 243 & $0.46 ; 0.55$ & & & $0.35 ; 0.49$ \\
\hline
\end{tabular}

In this study three sets of experiments were conducted at 298, 273 and $243 \mathrm{~K}$ for limonene, $\Delta^{3}$-carene and $\alpha$-pinene and each experimental set was further subdivided into three types of experiments: no scavenger or using 2-butanol or cyclohexane as $\mathrm{OH}$-scavenger. In every experimental run, the relative humidity was changed step-wise.

\section{Results and discussion}

\subsection{General observations}

Figure 1 shows an overview of the results from all experiments both regarding number and mass of particles produced. At $298 \mathrm{~K}$ the ozonolysis of limonene was the most efficient in producing SOA and $\alpha$-pinene the least, both regarding number and mass of particles formed (Jonsson et al., 2006). This outcome was observed for all scavenger situations. At 273 and $243 \mathrm{~K}$, the same trend was observed for number of particles formed, i.e. limonene $>\Delta^{3}$-carene $>\alpha$ pinene. However, the highest particle mass for experiments below room temperature was measured in the ozonolysis of $\Delta^{3}$-carene followed, in decreasing order, by limonene and finally $\alpha$-pinene. This order was observed for all scavenger conditions. For all three terpenes the reaction temperature affected the amount of SOA formed, both in number and mass (Fig. 1). For $\Delta^{3}$-carene and all three scavenger situations the highest number of particles was formed at a reaction temperature of $243 \mathrm{~K}$, followed by 273 and $298 \mathrm{~K}$.
However, the mass of particles produced decreased in the order $273>243 \gg 298 \mathrm{~K}$. The same order was obtained for $\alpha$ pinene except for the 2-butanol condition where a slightly higher mass yield was obtained at $243 \mathrm{~K}$ compared to $273 \mathrm{~K}$. For limonene the condition with cyclohexane followed the trend obtained for $\alpha$-pinene and $\Delta^{3}$-carene, both regarding number and mass. However, the behaviour for the limonene/2-butanol and without scavenger cases was different. The highest number of particles was formed at $273 \mathrm{~K}$ and the order for mass of particles formed was $273 \geq 298>243 \mathrm{~K}$.

\subsection{SOA production and temperature-partitioning effects}

The particle mass produced for each condition was normalised to the corresponding aerosol production at $298 \mathrm{~K}$, i.e. the ratio $\mathrm{M}(298 \mathrm{~K}) / \mathrm{M}(\mathrm{T})$ and is shown in Fig. 2. As indicated by Eq. (1), the SOA produced will increase with decreasing temperature due to favoured partitioning to the condensed phase at low temperatures. This means that if partitioning was the sole process taking place, the mass of particles formed would increase with a decrease in reaction temperature. This has been observed in several studies as summarised by Pathak et al. (2007b). However, recent results by Pathak et al. (2007b) illustrated that changes in chemical kinetics can offset this temperature dependence. In their experiments with ozonolysis of $\alpha$-pinene, the chemical part had a positive temperature dependence in the range $288-313 \mathrm{~K}$ and the partitioning part showed, as expected, a negative dependence with temperature. As shown in the present results, the highest mass yields were measured at $273 \mathrm{~K}$, which suggests that the kinetics and the distribution of products are altered by a changing reaction temperature. An alteration in the chemistry taking place at lower reaction temperatures is also supported by a change in volatility with decreasing reaction temperature (Jonsson et al., 2007). Physically, the greater mass of particles formed at $273 \mathrm{~K}$ compared to $243 \mathrm{~K}$ can be explained by more efficient nucleation at low temperatures (Fig. 1). That is, the mass at $243 \mathrm{~K}$ will be distributed onto many more particles than at $273 \mathrm{~K}$, i.e. partitioning over many smaller particles is favouring the gas phase due to the Kelvin effect. This will then explain the observations for $\alpha$-pinene and $\Delta^{3}$-carene that produces the highest number of particles at $243 \mathrm{~K}$ and the highest mass at $273 \mathrm{~K}$. However, for limonene this is not the case and we attribute this difference to dissimilarities in structure, i.e. limonene has two double bonds, one of which will be retained in the first generation of products, as discussed below for the temperature effect on new particle formation.

\subsection{SOA production and temperature-nucleation efficiency}

The increase in number of particles formed with decreasing temperature can be directly related to the fact that the saturation vapour pressure of any product is decreased at lower temperatures, hence increasing supersaturation and 


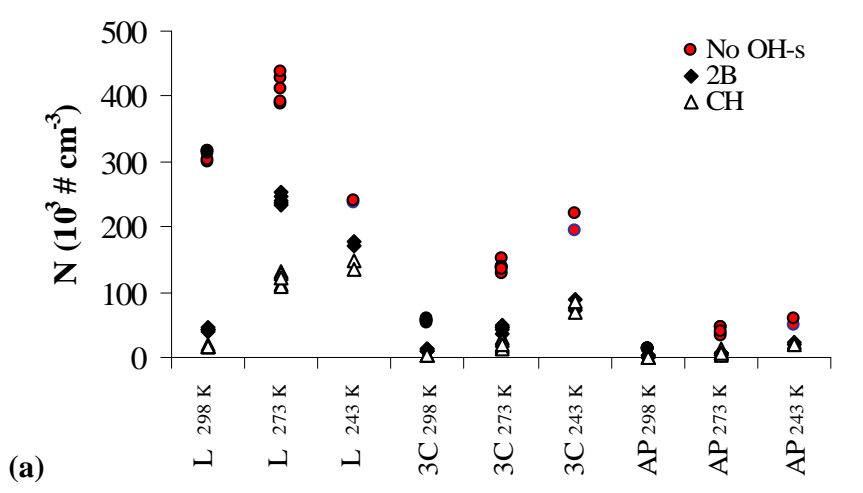

(b)

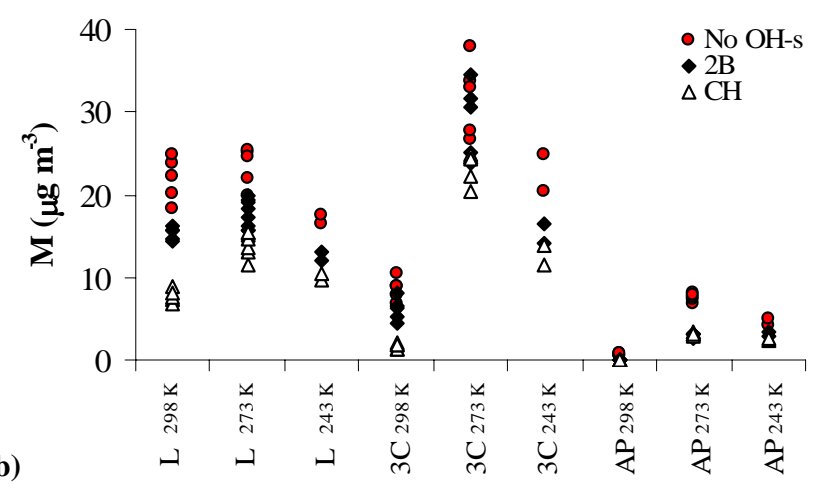

Fig. 1. (a) Particle number and (b) mass concentration of particles formed for all conducted experiments at $298 \mathrm{~K}, 273 \mathrm{~K}$ and $243 \mathrm{~K}$, and for a RH range from dry to $80 \%$. L is the abbreviation for limonene, AP for $\alpha$-pinene, $3 \mathrm{C}$ for $\Delta^{3}$-carene, $\mathrm{OH}$-s for $\mathrm{OH}$ scavenger, $2 \mathrm{~B}$ for 2-butanol and $\mathrm{CH}$ for cyclohexane.

nucleation rate for the same amount of products (Fig. 3). For each combination of scavenger and parent compound, the temperature dependence on nucleation is primarily dependent on product vapour pressures and distribution. An explanation of the results shown in Fig. 3 for the system without $\mathrm{OH}$-scavenger is that the products formed in the limonene ozonolysis are efficient in producing particles already at $298 \mathrm{~K}$ and therefore, a decrease in temperature does not significantly increase the nucleation $(13 \%$ enhancement at $\mathrm{N}(273 \mathrm{~K})$ and a $26 \%$ reduction in $\mathrm{N}(243 \mathrm{~K})$ compared to $\mathrm{N}(298 \mathrm{~K})$ ) (Fig. 3a). For $\alpha$-pinene and $\Delta^{3}$-carene the number of particles formed is increased considerably between $298 \mathrm{~K}$ and $273 \mathrm{~K}$. The enhancement is either due to products not contributing to nucleation at $298 \mathrm{~K}$, reaching high enough supersaturation to contribute at $273 \mathrm{~K}$ or to a change in product distribution caused by changes in kinetics and mechanisms at low temperature. Also for the systems using scavengers, there is an increase in the number of particles formed when going from $298 \mathrm{~K}$ to $273 \mathrm{~K}$. Further decrease in reaction temperature is generally causing an enhancement in nucleation. However, in some cases the nucleation efficiency is lower at $243 \mathrm{~K}$ than at $273 \mathrm{~K}$. One physical explanation for this temperature dependence is the competition between nucleation and condensation. The nucleation efficiency will be reduced if large aerosol surface is available and/or if the rate of producing the nucleating species is lower. For limonene, the complex temperature behaviour can be directly related to the more complex oxidation pathways, involving the oxidation of two double bonds. Zhang et al. indirectly showed that part of the limonene oxidation at low $\mathrm{NO}_{\mathrm{x}}$ conditions can be attributed to heterogeneous oxidation of the second double bond (Zhang et al., 2006). The change in temperature will then influence e.g. accommodation coefficients, liquid phase diffusion and solubility of ozone and organic reactants. This would cause a complex temperature effect on SOA mass, but how heterogeneous processing could influence the number of particles produced is not fully understood.

\subsection{SOA and radical chemistry}

All three terpenes investigated are known to have large $\mathrm{OH}$ yields from the reaction with ozone: limonene $0.86+0.43 /-0.29$ and $0.67 \pm 0.1 ; \quad \Delta^{3}$ Carene $1.06+0.53 /-0.36$ and $0.86 \pm 0.1 ; \quad \alpha$-pinene: $0.85+0.43 /-0.29, \quad 0.76 \pm 0.11, \quad 0.70 \pm 0.17, \quad 0.83 \pm 0.21$ and $0.91 \pm 0.23$ (Atkinson and Arey, 2003). It was shown that adding an $\mathrm{OH}$ scavenger affected the SOA production significantly, both in mass and number (Table 2). It was also shown that 2-butanol and cyclohexane gave different effects on the SOA formation, and where cyclohexane generally gave the least amount of SOA. In previous studies this has been attributed to a change in the peroxy radical chemistry (Docherty et al., 2005; Keywood et al., 2004). Table 2 is also showing the temperature effect on the scavenger-induced decrease in SOA formation caused by adding either 2-butanol or cyclohexane compared to the no-scavenger case. At $273 \mathrm{~K}$ and $243 \mathrm{~K}$ limonene and $\Delta^{3}$ carene show the same pattern with mass and number: $\mathrm{No} \mathrm{OH}$ scavenger $>2$-butanol $>$ cyclohexane. However, for $\alpha$-pinene the order is $\mathrm{NoOH}$ scavenger $>$ cyclohexane $\geq 2$-butanol. The difference in number of particles formed with and without an $\mathrm{OH}$ scavenger is becoming smaller with decreasing temperature (Table 2), suggesting less relative contribution of $\mathrm{OH}$ induced chemistry to particle formation at lower temperatures. As is seen in Table 2, for $\alpha$-pinene/2-butanol systems, the decrease is largest when going from $273 \mathrm{~K}$ to $243 \mathrm{~K}$. This is also the case for the $\alpha$-pinene/cyclohexane systems at high relative humidity, whereas the decrease is more notable in the 298 to $273 \mathrm{~K}$ range for dry conditions. In the limonene systems the effect is largest between 298 and $273 \mathrm{~K}$ for both 2-butanol and cyclohexane. For the $\Delta^{3}$-carene systems, the effect is dependent on the relative humidity. At dry conditions the change is largest in the range between 298 and $273 \mathrm{~K}$ whereas for humid conditions the change is largest between 273 and $243 \mathrm{~K}$. 


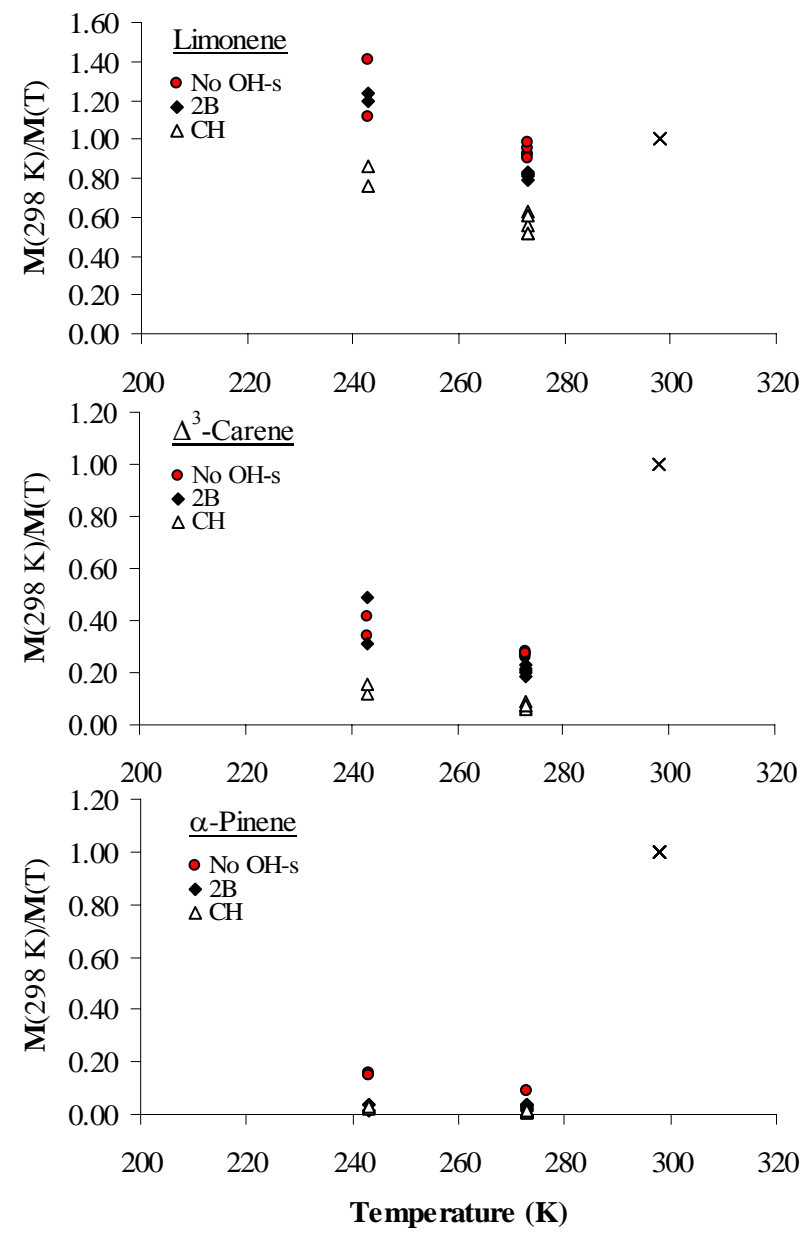

Fig. 2. Particle mass ratios normalised to $298 \mathrm{~K}$. The ratios at $298 \mathrm{~K}$ are per definition 1 and are indicated with a cross. Red circles: no $\mathrm{OH}$ scavenger (No OH-s), black diamonds: 2-butanol (2B), $\left(3.4 \times 10^{14}\right.$ molecules $\left.\mathrm{cm}^{-3}\right)$ and white triangles: cyclohexane $(\mathrm{CH}),\left(3.5 \times 10^{14}\right.$ molecules $\left.\mathrm{cm}^{-3}\right)$.

When comparing the mass of particles formed with or without an $\mathrm{OH}$ scavenger present, the results vary between the organic precursors (Table 2). The mass ratios for limonene experience small changes when the temperature is decreased. This is in contrast to the large decrease in number ratios when going down in temperature, which suggests different temperature dependence on the relative contribution of $\mathrm{OH}$ chemistry to condensing and nucleating compounds. In the $\alpha$-pinene systems the largest difference in mass ratio is seen between 298 and $273 \mathrm{~K}$. The very low mass ratio at $298 \mathrm{~K}(0.04-0.16)$ can be explained by the strong dependence of the partitioning on the particulate mass for low $\mathrm{M}_{0}$. For $\Delta^{3}$-carene the ratio between mass of particles produced without and with scavenger is largest at $273 \mathrm{~K}$. When using cyclohexane the ratio is changed the most in the temperature range 298-273 K, whereas in the 2-butanol case the change is very similar between the ranges.

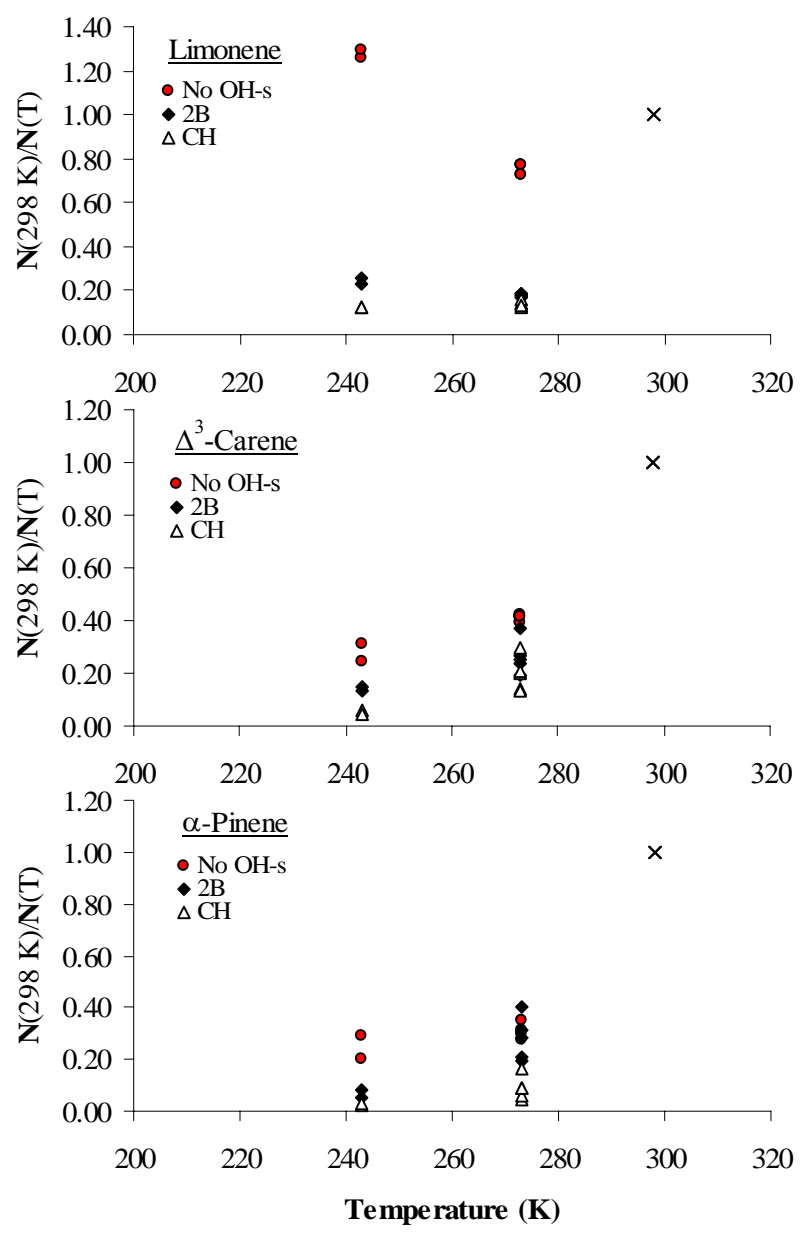

Fig. 3. Particle number ratios normalised to $298 \mathrm{~K}$. The ratios at $298 \mathrm{~K}$ are per definition 1 and are indicated with a cross. Red circles: no $\mathrm{OH}$ scavenger (No OH-s), black diamonds: 2-butanol (2B), $\left(3.4 \times 10^{14}\right.$ molecules $\left.\mathrm{cm}^{-3}\right)$ and white triangles: cyclohexane $(\mathrm{CH}),\left(3.5 \times 10^{14}\right.$ molecules $\left.\mathrm{cm}^{-3}\right)$.

The mechanistic explanation for the observed temperature effect regarding $\mathrm{OH}$ scavengers is rather speculative. It has been suggested from room temperature studies that the production of $\mathrm{OH}$ radicals in the ozonolysis of alkenes is either from the excited Criegee Intermediate, $\mathrm{CI}^{*}$, via the so called hydroperoxide channel (Calvert et al., 2000) or via the stabilised Criegee Intermediate, $\mathrm{CI}^{\mathrm{s}}$, in its reaction with water (Anglada et al., 2002). If the $\mathrm{OH}$ is from a decomposition process, and in competition with isomerisation or a bimolecular reaction one may expect an increasing $\mathrm{OH}$ yield with increasing temperature. However, the observations of changes in number and mass ratios with or without a scavenger for different temperatures can have other reasons than changes in $\mathrm{OH}$ yield. For example the kinetics of the secondary chemistry, such as $\mathrm{OH}$ reacting with the scavenger, can also be altered with temperature. From the present results it can thus be concluded that the $\mathrm{OH}$-induced SOA formation chemistry 
is changed while the reason is, so far, not established. Furthermore it is clear that the $\mathrm{OH}$ chemistry is active also at low temperatures, i.e. $\mathrm{OH}$ radicals are produced at $243 \mathrm{~K}$ in the ozonolysis of limonene, $\Delta^{3}$-carene and $\alpha$-pinene.

\subsection{Water effect on SOA formation}

As is seen in Table 3, water is influencing the formation of SOA, both regarding mass and number. This water influence is dependent on the reaction temperature. It should be noted that throughout this paper, relative humidity is used as the measure of water content. The absolute water saturation vapour pressure is strongly dependent on temperature. This implies that the investigated $\mathrm{RH}$ range corresponds to a much smaller change in absolute water concentration at $243 \mathrm{~K}$ compared to $298 \mathrm{~K}$. The direction and magnitude of the water effect is given in Table 3, where a positive sign implies more SOA being produced at higher relative humidity. The classification is done by comparing the lowest and highest relative humidity. However, in some cases the water dependence exhibits a local maximum or minimum at intermediate relative humidities.

For room temperature experiments, Jonsson et al., 2008 showed that the use of an $\mathrm{OH}$ scavenger as well as the type of scavenger influenced the water dependence on number and mass of particles formed in terpene ozonolysis (Jonsson et al., 2008). These results were confirmed in this study. For limonene, when using an $\mathrm{OH}$ scavenger, the same water effect is obtained at 298 and $273 \mathrm{~K}$. There is an increase in particles formed when using 2-butanol and a decrease in the number concentration with cyclohexane in the system. Without scavenger water had no impact on the number produced at $298 \mathrm{~K}$ whereas a positive effect was obtained at $273 \mathrm{~K}$. The negative effect of water when using cyclohexane was also found at $243 \mathrm{~K}$, however the water had no effect on number in the 2-butanol or no scavenger case. The effect of water is negative at high and intermediate temperatures for $\alpha$-pinene and $\Delta^{3}$-carene when having no $\mathrm{OH}$ scavenger in the system, whereas there is a positive effect at $243 \mathrm{~K}$. At high temperature the water effect is positive for all terpene/2-butanol systems. At intermediate temperature, $273 \mathrm{~K}$, the water effect is negative in most $\alpha$-pinene and $\Delta^{3}$-carene systems, whereas there is generally a slight positive water effect for these systems at $243 \mathrm{~K}$. There is a strong negative effect of water, a factor of two to three at $80 \%$ RH compared to dry for $\Delta^{3}$ carene and $\alpha$-pinene in the cyclohexane systems at $273 \mathrm{~K}$. The effect of the water concentration on the mass of particles formed is generally positive, except for the ozonolysis of $\alpha$-pinene/cyclohexane at $273 \mathrm{~K}$, where the mass of particles was indifferent to the concentration of water up to about $60 \% \mathrm{RH}$ and negative at higher RH.

The main features of the water dependence presented in Table 3 are that cyclohexane systems generally give a negative water dependence on particle number, while 2-butanol systems show a positive water effect and the system without
Table 3. Effect of relative humidity on number $(\mathrm{N})$ and mass (M) of particles formed in different scavenger systems. An increase is indicated with + , a decrease with - and no change is noted with 0 . Double symbols denote a change larger than $30 \%$. Local maxima or minima are denoted with $\wedge \vee$, respectively.

\begin{tabular}{|c|c|c|c|c|}
\hline $\mathrm{N}$ & & No OH-s & 2-Butanol & Cyclohexane \\
\hline \multicolumn{5}{|l|}{ Temp } \\
\hline \multirow[t]{3}{*}{$298 \mathrm{~K}$} & Limonene & 0 & + & - \\
\hline & $\Delta^{3}$-Carene & - & ++ & $\vee$ \\
\hline & $\alpha$-Pinene & - & ++ & ++ \\
\hline \multirow[t]{3}{*}{$273 \mathrm{~K}$} & Limonene & + & + & - \\
\hline & $\Delta^{3}$-Carene & - & - & -- \\
\hline & $\alpha$-Pinene & - & $\wedge$ & -- \\
\hline \multirow[t]{3}{*}{$243 \mathrm{~K}$} & Limonene & 0 & 0 & - \\
\hline & $\Delta^{3}$-Carene & + & + & + \\
\hline & $\alpha$-Pinene & + & + & 0 \\
\hline M & & No OH-s & 2-Butanol & Cyclohexane \\
\hline \multicolumn{5}{|l|}{ Temp } \\
\hline \multirow[t]{3}{*}{$298 \mathrm{~K}$} & Limonene & ++ & + & + \\
\hline & $\Delta^{3}$-Carene & ++ & ++ & ++ \\
\hline & $\alpha$-Pinene & + & ++ & ++ \\
\hline \multirow[t]{3}{*}{$273 \mathrm{~K}$} & Limonene & + & + & + \\
\hline & $\Delta^{3}$-Carene & ++ & ++ & + \\
\hline & $\alpha$-Pinene & + & + & $0<60 \%>-$ \\
\hline \multirow[t]{3}{*}{$243 \mathrm{~K}$} & Limonene & + & + & + \\
\hline & $\Delta^{3}$-Carene & + & + & + \\
\hline & $\alpha$-Pinene & + & + & + \\
\hline
\end{tabular}

scavenger shows a mixed behaviour depending on temperature and precursor. Concerning the mass of SOA produced most systems exhibit a positive dependence, which can be due to a physical and/or a chemical effect. At high temperatures ( 298 and $273 \mathrm{~K}$ ) the overall results demonstrated that there was not only a physical effect of water but also an influence of water on the chemical mechanism. This is based on water causing a larger increase in mass than expected from water uptake only, i.e. assuming a SOA hygroscopic growth factor of 1.07-1.09 (Cocker et al., 2001; Virkkula et al., 1999). Additionally, the influence of water on the formation of new particles, with reservation for cluster stabilisation, must be attributed to a change in rate of production/product distribution. The water effect is also dependent on the $\mathrm{OH}$ scavenger used, which again points towards water influencing the chemical degradation mechanism. The water effect at low temperature is much more consistent between the different situations and the magnitude of the SOA mass 
increase corresponds to physical absorption of water, i.e. less than a $30 \%$ mass increase. Consequently, the effect at $243 \mathrm{~K}$ could not exclude physical effects only, e.g. water uptake in combination with cluster stabilisation.

\section{Conclusions}

This paper extends earlier investigations on the ozonolysis of $\alpha$-pinene, $\Delta^{3}$-carene and limonene. The systems are now evaluated as a function of temperature and new insights into the ozonolysis are presented. The major conclusions from the work are outlined below. The water effect at low temperatures may be explained by physical uptake and cluster stabilisation, while at higher temperatures a physical explanation can not account for the observations. Water must therefore also cause changes in the chemical mechanism/rate of reactions. The differences concerning number and mass of particles formed between no-scavenger and scavenger experiments are generally reduced at low temperatures, especially when it comes to nucleation efficiency. However, these differences still exist at low temperatures, demonstrating that the $\mathrm{OH}$ chemistry is influencing the SOA formation also at these temperatures.

The overall temperature dependence of SOA formation is not as strong as expected from partitioning theory. In some cases there is even a positive dependence that must be related to changes in chemical mechanism and/or reaction rates at low temperatures. This is in line with previous studies on changes in chemical composition when going down in temperatures and findings from dedicated partitioning studies (Jonsson et al., 2007; Pathak et al., 2007b; Saathoff et al., 2008). It should be noted that the data presented are related to oxidation of rather small amounts of terpenes $(\sim 10 \mathrm{ppb}$ reacted) but on short time scales. This can discriminate observations of slow processes occurring over longer time scales (e.g. processes mimicking atmospheric ageing) but will limit artefacts such as interactions with the walls encountered in e.g. large simulation chambers. Another advantage is that all experiments can be compared after the same reaction time and with the same amount of terpene reacted and be directly comparable with the main focus to investigate the influence of changes in reaction conditions. Thus, as far as atmospheric implications are concerned, the results are related to the radical chemistry using 2-butanol as scavenger where the $\mathrm{HO}_{2}$ will have a dominant role i.e. in rural atmospheres at low $\mathrm{NO}_{\mathrm{x}}$ conditions. Further experiments are needed to constrain the chemistry occurring at high $\mathrm{NO}$ conditions when any produced peroxy radical $\left(\mathrm{RO}_{2}\right)$ will be converted via its NO reaction to alkoxy radicals (RO) or organic nitrates. The results obtained should be evaluated in relation to other methods, e.g. smog chamber experiments, and used for evaluation of chemical mechanisms and for increased understanding of SOA mass and new particle formation.
Acknowledgements. This work was supported by The Swedish Foundation for Strategic Environmental Research MISTRA, Formas under contract 214-2006-1204 and the Graduate school "Climate and Mobility", University of Gothenburg. SaabTechGöteborg is acknowledged for the donation of the temperature chamber. Senior Research Engineer, Benny Lönn, provided skilful technical support.

Edited by: J. Thornton

\section{References}

Anglada, J. M., Aplincourt, P., Bofill, J. M., and Cremer, D.: Atmospheric formation of $\mathrm{OH}$ radicals and $\mathrm{H}_{2} \mathrm{O}_{2}$ from alkene ozonolysis under humid conditions, Chem. Phys. Chem., 3, 215-221, 2002.

Anttila, T., Kerminen, V. M., Kulmala, M., Laaksonen, A., O'Dowd, C. D.: Modelling the formation of organic particles in the atmosphere, Atmos. Chem. Phys., 4, 1071-1083, 2004, http://www.atmos-chem-phys.net/4/1071/2004/.

Atkinson, R.: Gas-phase tropospheric chemistry of organiccompounds, J. Phys. Chem. Ref. Data, 1, R1-R216, 1994.

Atkinson, R. and Arey, J.: Gas-phase tropospheric chemistry of biogenic volatile organic compounds: a review, Atmos. Environ., 37, S197-S219, 2003.

Atkinson, R., Baulch, D. L., Cox, R. A., Crowley, J. N., Hampson, R. F., Hynes, R. G., Jenkin, M. E., Rossi, M. J., and Troe, J.: Evaluated kinetic and photochemical data for atmospheric chemistry: Volume II - gas phase reactions of organic species, Atmos. Chem. Phys., 6, 3625-4055, 2006, http://www.atmos-chem-phys.net/6/3625/2006/.

Burkholder, J. B., Baynard, T., Ravishankara, A. R., and Lovejoy, E. R.: Particle nucleation following the $\mathrm{O}_{3}$ and $\mathrm{OH}$ initiated oxidation of $\alpha$-pinene and $\beta$-pinene between 278 and 320 K. J. Geophys. Res.-Atmos., 112, D10216, 2007.

Calvert, J. G., Atkinson, R., Kerr, J. A., Madronich, S., Moortgat, G. K., Wallington, T. J., and Yarwood, G.: The Mechanism of Atmospheric Oxidation of the Alkenes, Oxford University Press, New York, USA, 552 pp., 2000.

Camredon, M., Aumont, B., Lee-Taylor, J., and Madronich, S.: The SOA/VOC/NOx system: an explicit model of secondary organic aerosol formation, Atmos. Chem. Phys., 7, 5599-5610, 2007, http://www.atmos-chem-phys.net/7/5599/2007/.

Cocker, D. R., Clegg, S. L., Flagan, R. C., and Seinfeld, J. H.: The effect of water on gas-particle partitioning of secondary organic aerosol. Part I: $\alpha$-pinene/ozone system, Atmos. Environ., 35, 6049-6072, 2001.

Docherty, K. S., Wu, W., Lim, Y. B., and Ziemann, P. J.: Contributions of organic peroxides to secondary aerosol formed from reactions of monoterpenes with $\mathrm{O}_{3}$, Environ. Sci. Technol., 39, 4049-4059, 2005.

Donahue, N. M., Robinson, A. L., Stanier, C. O., and Pandis, S. N.: Coupled partitioning, dilution, and chemical aging of semivolatile organics, Environ. Sci. Technol., 40, 2635-2643, 2006.

Goldstein, A. H. and Galbally, I. E. Known and unexplored organic constituents in the earth's atmosphere, Environ. Sci. Technol., 41, 1514-1521, 2007. 
Griffin, R. J., Cocker, D. R., Flagan, R. C., and Seinfeld, J. H.: Organic aerosol formation from the oxidation of biogenic hydrocarbons, J. Geophys. Res-Atmos., 104, D03201(D3), 3555-3567, 1999.

Guenther, A.: The contribution of reactive carbon emissions from vegetation to the carbon balance of terrestrial ecosystems, Chemosphere, 49, 837-844, 2002.

Guenther, A., Hewitt, C. N., Erickson, D., Fall, R., Geron, C., Graedel, T., Harley, P., Klinger, L., Lerdau, M., McKay, W. A., Pierce, T., Scholes, B., Steinbrecher, R., Tallamraju, R., Taylor, J., and Zimmerman, P.: A global-model of natural volatile organic-compound emissions, J, Geophys, Res.-Atmos., 100, 8873-8892, 1995.

Jang, M. and Kamens, R. M.: Newly characterized products and composition of secondary aerosols from the reaction of alphapinene with ozone, Atmos. Environ., 33, 459-474, 1999.

Jenkin, M. E.: Modelling the formation and composition of secondary organic aerosol from alpha- and beta-pinene ozonolysis using MCM v3, Atmos. Chem. Phys., 4, 1741-1757, 2004, http://www.atmos-chem-phys.net/4/1741/2004/.

Jonsson, Å. M., Hallquist, M., Ljungström, E.: Impact of humidity on the ozone initiated oxidation of limonene, $\Delta^{3}$-carene, and $\alpha$ pinene, Environ. Sci. Technol., 40, 188-194, 2006.

Jonsson, Å. M., Hallquist, M., and Saathoff, H.: Volatility of secondary organic aerosols from the ozone initiated oxidation of $\alpha$ pinene and limonene, J. Aerosol Sci., 38, 843-852, 2007.

Jonsson, ̊. M., Hallquist, M., and Ljungström, E.: Influence of $\mathrm{OH}$ scavenger on the water effect on secondary organic aerosol formation from ozonolysis of limonene, $\Delta^{3}$-Carene, and $\alpha$-Pinene. Environ. Sci. Technol., 42, 5938-5944, 2008.

Kanakidou, M., Seinfeld, J. H., Pandis, S. N., Barnes, I., Dentener, F. J., Facchini, M. C., Van Dingenen, R., Ervens, B., Nenes, A., Nielsen, C. J., Swietlicki, E., Putaud, J. P., Balkanski, Y., Fuzzi, S., Hjorth, J., Moortgat, G. K., Winterhalter, R., Myhre, C. E. L., Tsigaridis, K., Vignati, E., Stephanou, E. G., and Wilson, J.: Organic aerosol and global climate modelling: a review, Atmos. Chem. Phys., 5, 1053-1123, 2005,

http://www.atmos-chem-phys.net/5/1053/2005/.

Keywood, M. D., Kroll, J. H., Varutbangkul, V., Bahreini, R., Flagan, R. C., and Seinfeld, J. H. Secondary organic aerosol formation from cyclohexene ozonolysis: Effect of $\mathrm{OH}$ scavenger and the role of radical chemistry, Environ. Sci. Technol., 38, 3343$3350,2004$.

Khamaganov, V. G. and Hites, R. A.: Rate constants for the gasphase reactions of ozone with isoprene, $\alpha$ - and $\beta$-pinene, and limonene as a function of temperature, J. Phys. Chem. A, 105, 815-822, 2001.
Odum, J. R., Hoffmann, T., Bowman, F., Collins, D., Flagan, R. C., and Seinfeld, J. H.: Gas/particle partitioning and secondary organic aerosol yields, Environ. Sci. Technol., 30, 2580-2585, 1996.

Pankow, J. F.: An absorption-model of the gas aerosol partitioning involved in the formation of secondary organic aerosol, Atmos. Environ., 28, 189-193, 1994.

Pathak, R. K., Presto, A. A., Lane, T. E., Stanier, C. O., Donahue, N. M., and Pandis, S. N.: Ozonolysis of $\alpha$-pinene: parameterization of secondary organic aerosol mass fraction, Atmos. Chem. Phys., 7, 3811-3821, 2007a http://www.atmos-chem-phys.net/7/3811/2007/.

Pathak, R. K., Stanier, C. O., Donahue, N. M., and Pandis, S. N.: Ozonolysis of alpha-pinene at atmospherically relevant concentrations: Temperature dependence of aerosol mass fractions (yields), J. Geophys. Res.-Atmos., 112, 2007b.

Saathoff, H., Naumann, K. H., Möhler, O., Jonsson, Å. M., Hallquist, M., Kiendler-Scharr, A., Mentel, T. F., Tillmann, R., and Schurath, U.: Temperature dependence of yields of secondary organic aerosols from the ozonolysis of $\alpha$-pinene and limonene, Atmos. Chem. Phys. Discuss., 8, 15 595-15 664, 2008, http://www.atmos-chem-phys-discuss.net/8/15595/2008/.

Takekawa, H., Minoura, H., Yamazaki, S.: Temperature dependence of secondary organic aerosol formation by photo-oxidation of hydrocarbons, Atmos. Environ., 37, 3413-3424, 2003.

Tsigaridis, K. and Kanakidou, M.: Global modelling of secondary organic aerosol in the troposphere: a sensitivity analysis, Atmos. Chem. Phys., 3, 1849-1869, 2003, http://www.atmos-chem-phys.net/3/1849/2003/.

Went, F. W.: Blue hazes in the atmosphere, Nature, 187, 641-643, 1960.

Virkkula, A., Van Dingenen, R., Raes, F., and Hjorth, J.: Hygroscopic properties of aerosol formed by oxidation of limonene, $\alpha$-pinene, and $\beta$-pinene, J. Geophys. Res.-Atmos., 104, 35693579, 1999.

Yokouchi, Y. and Ambe, Y.: Aerosols formed from the chemicalreaction of monoterpenes and ozone, Atmos. Environ., 19, 12711276, 1985.

Zhang, J. Y., Hartz, K. E. H., Pandis, S. N., and Donahue, N. M.: Secondary organic aerosol formation from limonene ozonolysis: Homogeneous and heterogeneous influences as a function of $\mathrm{NO}_{\mathrm{x}}$, J. Phys. Chem. A, 110, 11 053-11 063, 2006. 